\title{
Traumatic hemisomato-tmesis: a case report and review of the literature
}

\author{
S. J. WALKER \& R. H. JOHNSON \\ Department of Surgery, Whiston Hospital, Prescot, England
}

\section{SUMMARY}

A case of traumatic hemisomato-tmesis is presented. The line of complete transection passed obliquely from the suprapubic skin to the lumbosacral junction. There were associated visceral injuries. We describe our experience of such a case and review the surgical options in the light of the current literature.

\section{INTRODUCTION}

Traumatic hemisomato-tmesis is a very rare injury in peace time, with most patients dying before they reach hospital. With improved emergency care it is possible that in the future such a patient may achieve long-term survival. We describe our experience of $\exists$ such a case and review the treatment options in the light of the limited available literature.

\section{CASE REPORT}

A 20-year-old-woman attempted to commit suicide by throwing herself in front of a moving train. She had a history of behavioural problems and had previously taken two drug overdoses. On reaching hospital she was found to have sustained a complete $\widetilde{N}$ corporal transection. The line of transection passed obliquely from the suprapubic skin $N$ towards the lumbosacral junction with significant skin loss of her back. The lower limbs

Correspondence: Mr S. F. Walker, University Department of Surgery, Royal Liverpool Hospital, PO Box 147, Liverpool L69 3BX, England. 
and pelvis were separate and intact. There were no other injuries and the patient was fully conscious. Initial observations revealed a pulse rate of 100 beats per min and a systolic blood pressure of $50 \mathrm{mmHg}$. There was significant bleeding at the site of transection from the spinal muscles and bone but only a small amount from the common iliac arteries which were in spasm. The arteries were clamped and the patient resuscitated. She was aware of the nature of her injury and wished for further treatment.

Under general anaesthesia the bladder, vagina and lower rectum were found to have been avulsed and a $40-\mathrm{cm}$ segment of terminal ileum perforated and torn from its mesentery. The damaged small bowel was resected and an end-to-end anastomosis performed. The sigmoid colon was brought out as an end colostomy and both ureters mobilized and brought out separately as end ureterostomies (Fig. 1). The common iliac vessels were transfixed. In view of the extensive skin loss of her lower back the remains of the left iliac crest, sacrum and fifth lumbar vertebra were excised to allow the viable anterior flaps to meet the reduced posterior flap. The estimated blood loss during the 3$\mathrm{h}$ operation was $10 \mathrm{l}$. She died $2 \mathrm{~h}$ later and we ascribe this to a combination of hypovolaemia, cardiac arrythmia and biochemical imbalance.

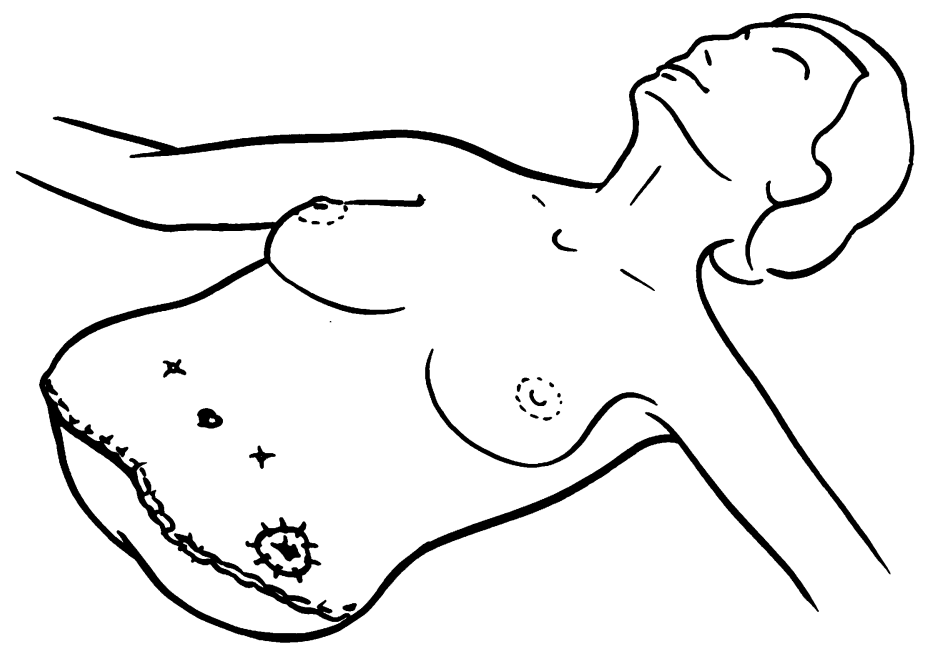

Fig. 1 Line diagram of patient at the end of the operation to show position of end-colostomy and endureterostomies.

\section{DISCUSSION}

We are unaware of any similar reports of traumatic transection. The lesser injury of hemipelvic section has infrequently been described but its overall incidence and mortality is unknown (Rodrigues-Morales et al., 1983). Open fracture of the pelvis may be associated with a $50 \%$ mortality (Rothenberger et al., 1978). Baker et al. in 1970 reported a case of severe crush injury which subsequently required a translumbar amputation. Elective hemicorporectomy has been irregularly reported since 1960 (Kennedy et al., 1960). It is believed that up to 30 may have been performed to date for advanced sacral and pelvic malignancy, osteomyelitis, or skin ulceration (Yancey et al., 
1964; Miller et al., 1966; Williams \& Fish, 1969; Norris et al., 1973; Davis et al., 1975; Pearlman et al., 1976). Only one-third of these have enjoyed long-term survival (Elliotto \& Alexander, 1982), results which are probably little different from those seen after 3 hemipelvectomy for carcinomas involving the upper thigh (Sherman \& Duthie, 1960). $?$ The ethical aspects of elective hemicorporectomy have received attention (Simecek \& Kralik, 1975).

Active treatment of an injury such as this may be questioned and must depend on the $\frac{\bar{c}}{\bar{n}}$ individual circumstances. There are frequent accounts of patients recovering from $\overrightarrow{\vec{\sigma}}$ apparently hopeless injuries to lead useful lives. Independent assessment of four patients who had undergone elective hemicorporectomy suggests that they viewed the ${ }_{-}^{\infty}$ procedure as having been worthwhile (Miller et al., 1966). In this case the decision was. made easier by the fact that the patient requested treatment, there were no other injuries $\overrightarrow{\vec{\omega}}$ and we were initially unaware of her past medical history. Had we not treated her she $\stackrel{\odot}{\Phi}$ would have posed a difficult and distressing nursing problem until she died.

Management should be no different from that of any other severely injured patient..$\dot{9}$ Early surgical treatment consists of control of haemorrhage, wound debridement, $\delta$ achieving skin cover and appropriate faecal and urinary diversion. Significant bleeding@ from the posterior abdominal wall and spine proved difficult to control. Similar problems were reported in patients after traumatic hemipelvic section (Rodrigues- $\frac{3}{\mathrm{~N}}$ Morales $e t$ al., 1983). Because of the disproportionate sizes of the anterior and posterior flaps, skin cover could not be achieved and this was managed by further resection of $\overrightarrow{0}$ bone. An alternative approach would have been to use the skin taken from the lowero torso (Oppenheim et al., 1977). We did not attempt to close the dura but this omission might have subsequently led to the development of meningitis (Baker et al., 1970). The possibility of reimplantation of the pelvis was considered but the patient was judged to be too ill and this untried and technically difficult procedure inappropriate.

Both elective and traumatic corporal transection has important physiological and $\stackrel{\triangleright}{\circ}$ anaesthetic implications. The body weight is reduced by $40-55 \%$ and fluid require- $\overrightarrow{\overrightarrow{0}}$ ments and drug doses need to be adjusted appropriately. The reduction in muscle mass may have an effect on the body's ability to regulate circulating volume and maintain acid-base balance (Elliott \& Alexander, 1982). Marked changes have been reported in cardiac and respiratory function, thermoregulation, regional ventilation and gas 3 exchange (Lamis et al., 1967; Grimby \& Stener, 1973; Bake \& Grimby, 1974).

Had our patient survived, the post-operative period was likely to have been eventful. The mortality of patients after open pelvic fracture is reported as $50 \%$ due to haemorrhage, sepsis and renal failure (Rothenberger et al., 1978). Death after electiveo hemicorporectomy has been caused by recurrent disease, pulmonary oedema and $\bar{D}$ toxaemia. The patient reported by Baker et al. (1970) had a stormy post-operative? course and subsequently required numerous procedures over a 6-month period to 0 achieve skin cover. Rehabilitation is demanding on the patient and staff, consisting of 0 physiotherapy and occupational therapy and the development of suitable 'bucket' prostheses which may eventually allow limited walking (Easton et al., 1963; Delateur et al., 1969; Davis et al., 1975). 


\section{REFERENCES}

Bake B \& Grimby G. (1974) Regional ventilation and gas exchange after hemicorporectomy. Thorax 29, 36670.

Baker T. C., Berkowitz T., Lord G. B. \& Hankins H. V. (1970) Hemicorporectomy. British fournal of Surgery 57, 471-6.

Davis S. W., Chu D. S. \& Yang C. J. (1975) Translumber amputation for nonneoplastic cause: rehabilitation and follow-up. Archives of Physical and Medical Rehabilitation 56, 359-62.

Delateur J. B., Lehmann J. F., Winterscheid L. C., et al. (1969) Rehabilitation of patient after hemicorporectomy. Archives of Physical and Medical Rehabilitation 50, 11-16.

Easton J. K., Dawson W. J. Jr. \& Kottke F. J. (1963) Fitting of prosthesis on patient after hemicorporectomy. Archives of Physical and Medical Rehabilitation 44, 335-7.

Elliott P. \& Alexander J. P. (1982) Translumber amputation: a case report. Anaesthesia 37, 576-81.

Grimby G. \& Stener B. (1973) Physical performance and cardio-respiratory function after hemicorporectomy. Scandinavian fournal of Rehabilitation Medicine 5, 124-9.

Kennedy C. S., Miller E. B., McLean D. C., et al. (1960) Lumber amputation or hemicorporectomy for advanced malignancy of the lower half of the body. Surgery 48, 357-65.

Lamis P. A., Richards A. J. Jr., Weidner M. G. Jr. (1967) Hemicorporectomy: hemodynamic and metabolic problems. American Surgeon 33, 443-8.

Miller T. R., Mackenzie A. R. \& Randall H. T. (1966) Translumber amputation for advanced cancer: indications and physiologic alterations in four cases. Annals of Surgery 164, 514-21.

Norris J. E. C., Kwon Y. B., Puangsuvan S. \& Watkins W. E. (1973) Hemicorporectomy: a case report. Am Surgeon 39, 344-8.

Oppenheim W. L., Tricker J. \& Smith R. B. (1977) Traumatic hemipelvectomy, the 10th survivor: a case report and review of the literature. Injury $9,307-12$.

Pearlman N. W., McShane R. H., Jochimsen P. R. \& Shirazi S. S. (1976) Hemicorporectomy for intractable decubitas ulcers. Archives of Surgery 111, 1139-43.

Rodrigues-Morales G., Phillips T., Conn A. K. \& Cox E. F. (1983) Traumatic hemipelvectomy: report of two survivors and review. Fournal of Trauma 23, 615-20.

Rothenberger D., Velasco R., Strate R., et al. (1978) Open-pelvic fracture: a lethal injury. fournal of Trauma $18,184-7$.

Sherman C. D. \& Duthie R. B. (1960) Modified hemipelvectomy. Cancer 13, 51-4.

Simecek O. \& Kralik J. (1975) Erwagungen über die Ethische Berechtigung der Hemikorpektomie. Zantralblatt für Chirurgie 100, 812-15.

Williams R. D. \& Fish J. C. (1969) Translumber amputation. Cancer 23, 416-8.

Yancey A. G., Ryan H. F. \& Blasingame J. T. (1964) An experience with hemicorporectomy. fournal of the National Association 56, 323-5. 